\title{
PROPERTIES OF AN EXTRUSION ENERGY ABSORBER
}

\author{
W. H. Robinson* and L. R. Greenban k**
}

\section{ABSTRACT}

By pushing lead back and forth through an orifice the process of extrusion can be used to absorb energy. When the lead is extruded it recrystallizes immediately, thereby regaining its original mechanical properties. Rather than the energy absorber being limited by the strength and work hardening of the lead it is limited by the heat capacity of the device and is therefore able to absorb energy during a number of earthquakes. To date extrusion energy absorbers of $20 \mathrm{kN} \times 2 \mathrm{~cm}$ stoke to $200 \mathrm{kN} \times 26 \mathrm{~cm}$ stroke have been tested at rates of $2 \times 10^{-8}$ to $60 \mathrm{~cm} / \mathrm{sec}$ and they behaved as "coulomb dampers" with nearly rectangular hysteresis loops and little rate dependence.

\section{INTRODUCTION}

Large structures in earthquake-prone areas require some means of damping the oscillations induced in them by earthquakes. If there is no damping or energy absorbing component incorporated in the structure these oscillations may, in a severe earthquake, build up to such a level that the structure is seriously damaged or destroyed. A possible approach to the problem is to incorporate energy absorbing devices in the structure instead of relying on the structure inself to provide the damping (1). A number of authors $(2-4)$ have examined the effect of a "coulomb damper" on the response of a structure for an earthquake and in this paper we discuss the properties of an extrusion energy absorber which behaves like a "coulomb damper".

\section{EXTRUSION ENERGY ABSORBER}

A good way of absorbing energy is by the plastic deformation of a metal or other material. A simple means of producing severe plastic deformation in a material is by extrusion $(5,6)$, which may be defined as the process by which a block of material is forced by compression to flow through an orifice of smaller cross-sectional area than the original block (Figure 1 ).

The pressure applied to the ram forces the material to flow through the orifice, producing a microstructure of elongated grains containing many crystal lattice defects. A proportion of the energy required to extrude the material appears immediately as heat, but some is stored in the deformed material and is the primary driving force for the three interrelated processes - recovery, recrystallization and grain growth - which tend to restore the material to its original condition $(7,8)$. The extent to which the original conditions are regained is a function of temperature, time and the degree of deformation, and varies widely depending on the material.

* Scientist

** Technician

Material Science Section, Physics and

Engineering Laboratory, D.S.I.R.,

Lower Hutt, New Zealand.
For example, deformed lead will completely recover its properties at room temperature in less than 10 seconds. Copper at the same temperature takes about 100 years to recover its properties, but if it is heated to $100^{\circ} \mathrm{C}$ the process takes about three hours. A term commonly used to summarize these processes in metals is the recrystallization temperature - this is the temperature at which the highly coldworked metal completely recrystallizes, thereby regaining most of its original properties, in about one hour.

A device $(9,10)$ suitable for incorporation into structures as an energyabsorbing component is shown in Fig. 1. Essentially it consists of a thick-walled tube having a construction, on either side of which are two pistons connected by a tie rod. The space between the pistons is filled with lead, which is separated from the cylinder wall by a thin layer of lubricant kept in place by hydraulic seals around the pistons. One piston is effectively part of a connecting rod which extends beyond one end of the cylinder and is fixed to the structure, while the opposite end of the cylinder is fixed to another part of the structure. When the two parts of the structure oscillate relative to each other (as during an earthquake) the lead is extruded back and forth through the orifice. Since extrusion is a process of plastic deformation, work must be done as the pistons move relative to the cylinder - i.e. as the structure deforms. Thus in an earthquake protection application such a device would, by absorbing energy, limit the build-up of destructive oscillations in the structure.

The successful operation of this device depends on the use of a cyclically extrudable material - in this case lead. Lead has a recrystallization temperature well below room temperature $(-50 \mathrm{C})(7)$ so the force required to extrude it is practically the same on each successive cycle. It has been found that lead is cyclically extrudable at an ambient temperature as low as $-20^{\circ} \mathrm{C}$. It is assumed that the cold work done on the lead raises its temperature in the region of the orifice to a point where the recrystallization 
time is short.

The work done per cycle depends on the length of stroke and the extrusion force. The extrusion force depends on the material, the extrusion ratio, the cross-sectional area and, to a very limited extent, on the rate of extrusion. Figure 2 shows typical force-displacement curves obtained using a $250 \mathrm{kN}$ Instron Universal Testing Machine for two lead filled extrusion energy absorbers. The results shown in figure $2 a$ are for a device in which the orifice is formed by a constricted tube as in figure 1 while the curve in figure $2 \mathrm{~b}$ is for a device in which a bulge on a shaft is moved through the lead. The performance factors (curve area/enclosing rectangle) are 0.79 and 0.93 respectively. The elastic portion of the force-displacement diagram for these devices is less than $1 \mathrm{~mm}$ while their total strokes are $2 \mathrm{~cm}$ and $15.2 \mathrm{~cm}$.

In figure 3 are the results for the rate dependence of a number of extrusion energy absorbers tested at speeds in the range $2 \times 10^{-8}$ to $60 \mathrm{~cm} / \mathrm{sec}$. The results at speeds of $0.17 \mathrm{~cm} / \mathrm{sec}(10 \mathrm{~cm} / \mathrm{min})$ and less were obtained using the Instron machine, the one result at $1.7 \mathrm{~cm} / \mathrm{sec}\left(10^{2} \mathrm{~cm} / \mathrm{min}\right)$ was obtained using PACRA's $450 \mathrm{kN}$ structural loading system (MTS model 904.09), while the value at $\sim 60 \mathrm{~cm} / \mathrm{sec}\left(\sim 3.6 \times 10^{3} \mathrm{~cm} / \mathrm{min}\right)$ was obtained by dropping a $62 \mathrm{~kg}$ weight on a $20 \mathrm{kN}$ energy absorber. The results in figure 3 can be described by a normalised equation of the form

$$
F / F\left(V_{1}\right)=\left(V / V_{1}\right)^{b}
$$

where $F$ is the force to operate the absorber, $\mathrm{V}$ is the speed and $\mathrm{b}$ is a constant. Below a speed of $1.7 \times 10^{-3} \mathrm{~cm} / \mathrm{sec}$ the index $\mathrm{b}$ is 0.12 giving a load increase of $32 \%$ for a ten-fold increase in operating speed. Above $1.7 \times 10^{-3} \mathrm{~cm} / \mathrm{sec}\left(10^{-1} \mathrm{~cm} / \mathrm{min}\right) \mathrm{b}$ becomes 0.03 so that a $7 \%$ increase in load occurs for a rate increase by a factor of ten. The extrusion energy absorber therefore has very little rate dependence at earthquake-like speeds of $10 \mathrm{~cm} / \mathrm{sec}\left(6 \times 10^{2} \mathrm{~cm} / \mathrm{min}\right)$ and furthermore in the range $1 \mathrm{~cm} /$ year to 60 $\mathrm{cm} / \mathrm{sec}$ the operating force increases by a factor of six.

To gauge the number of cycles which an extrusion energy absorber can withstand, a $15 \mathrm{kN}$ constricted-tube device was operated continuously at frequencies of $0.5,1$ and $2 \mathrm{~Hz}$ for a total of 3,400 cycles. After this test the device was found to operate as before at $1.7 \times 10^{-2} \mathrm{~cm} / \mathrm{sec}$ suggesting that it should be able to cope with a number of earthquakes.

The dimensions of a $150 \mathrm{kN}$ energy absorber with a stroke of $\pm 20 \mathrm{~cm}$ are

$$
\begin{array}{ll}
\text { outside diameter } & \sim 15 \mathrm{~cm} \text { and } \\
\text { total length } & \sim 150 \mathrm{~cm} \text {, with } \\
\text { total weight } & \sim 100 \mathrm{~kg} .
\end{array}
$$

\section{CONCLUSION}

The extrusion energy absorber using lead as the extruded material is a device which operates like a "coulomb damper" in that its force-displacement curve is nearly rectangular and its rate dependence at earthquake-like speeds is small.

\section{ACKNOWLEDGEMENTS}

The authors wish to thank Mr. R. I. Skinner for advising them of the need for energy absorbers for the protection of structures from earthquake damage.

\section{REFERENCES}

1. Skinner, R. I., Kelly, J. M. and Heine, A. J. (1973). "Energy Absorption Devices for Earthquake Resistant Structures." Proc. 5th Wld. Conf. Earthq. Engng, Session 8C, Rome, Italy.

2. Skinner R. I., Beck J. L. and Bycroft G. N. (1975). "A Practical System for Isolating structures from Earthquake Attack." Int. J. Earthq. Engng. and Struct. Dynamics. Vol. 3, No. 3.

3. Skinner R. I., and McVerry, G. H. (1975). "Base Isolation for Increased Earthquake Resistance of Buildings." South Pacific Regional Conference on Earthquake Engineering.

4. Mayes, R. I. (1975). "The Effect of Coulomb Damping on the Response of Structures." South Pacific Regional Conference on Earthquake Engineering.

5. Pearson, C. E. (1944). "The Extrusion of Metals." John Wiley and Sons.

6. Pugh, H. U. D. (1970). "Hydrostatic Extrusion, in Mechanical Behaviour of Materials under Pressure" (Ed. H. U. D. Pugh). Applied Science Pub. London.

7. Wulff J., Taylor J. F. and Shaler A. J. (1956). "Metallurgy for Engineers." John Wiley and Sons, New York.

8. Birchenall C. E. (1959). "Physical Metallurgy." MCGraw-Hill.

9. Robinson W. H. (1972). "A Cyclic Extrusion Energy Absorber." N.Z. Patent 165,897. U.S.A. Patent $317,431$.

10. Robinson W. H. and Greenbank L. R. (1975). An Extrusion Energy Absorber Suitable for the protection of

Structures During an Earthquake. Int. J. Earthg. Engng. and Struct. Dynamics. Vol. 3 . 


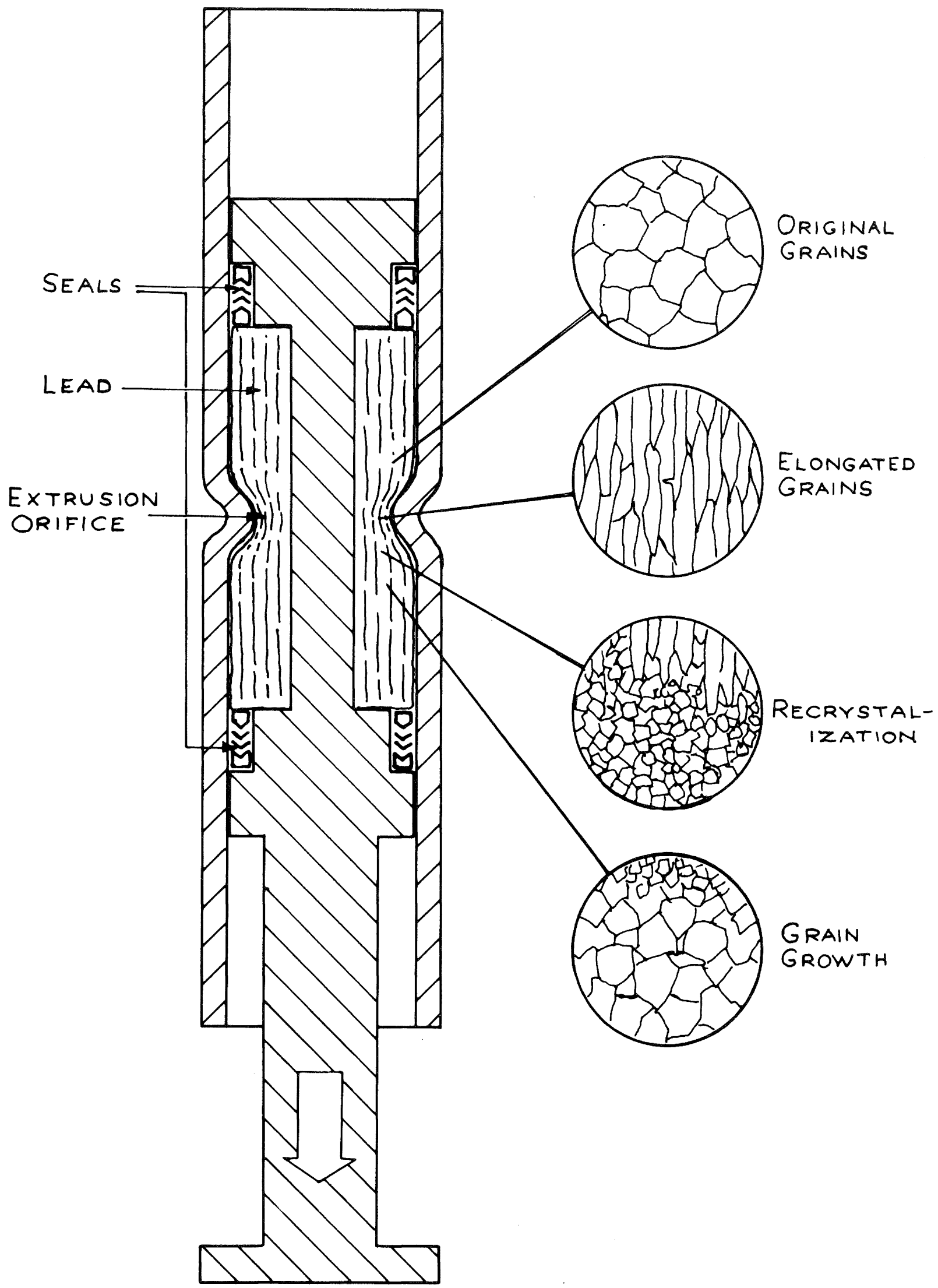




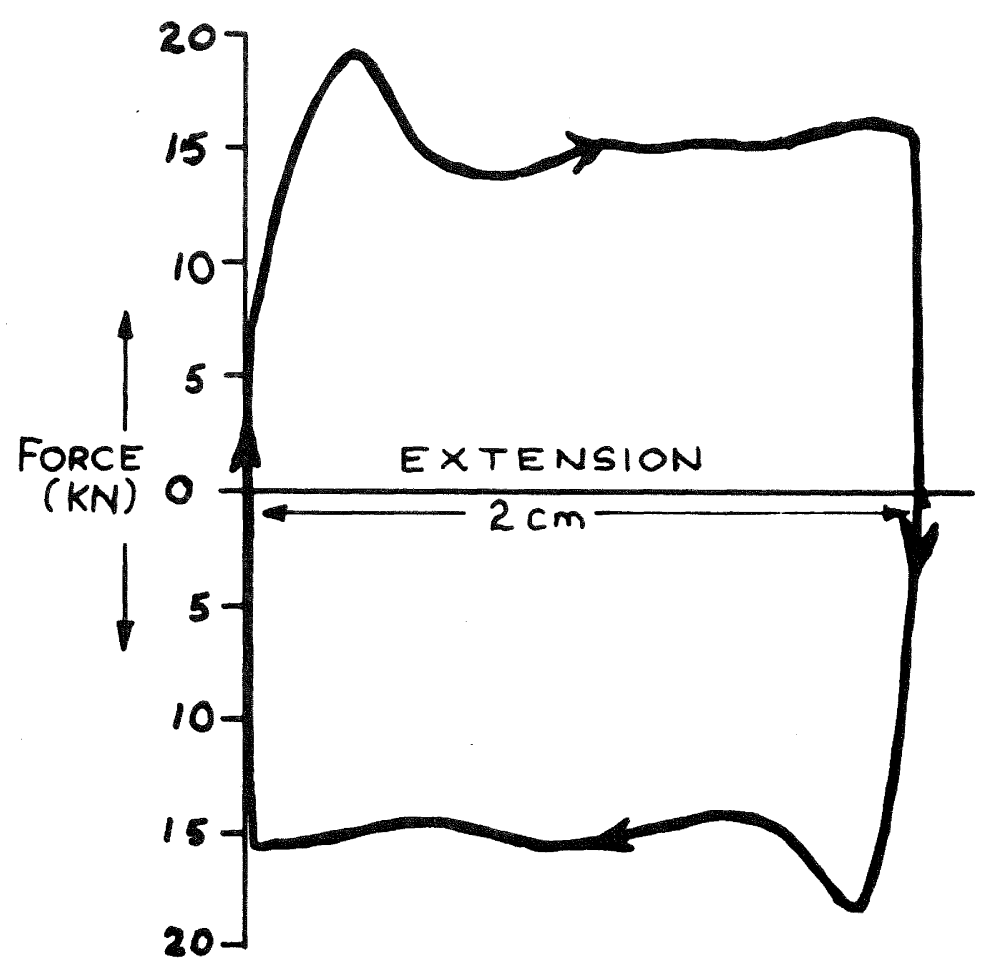

(a) $15 \mathrm{kN}$ CONSTRICTED-TUBE

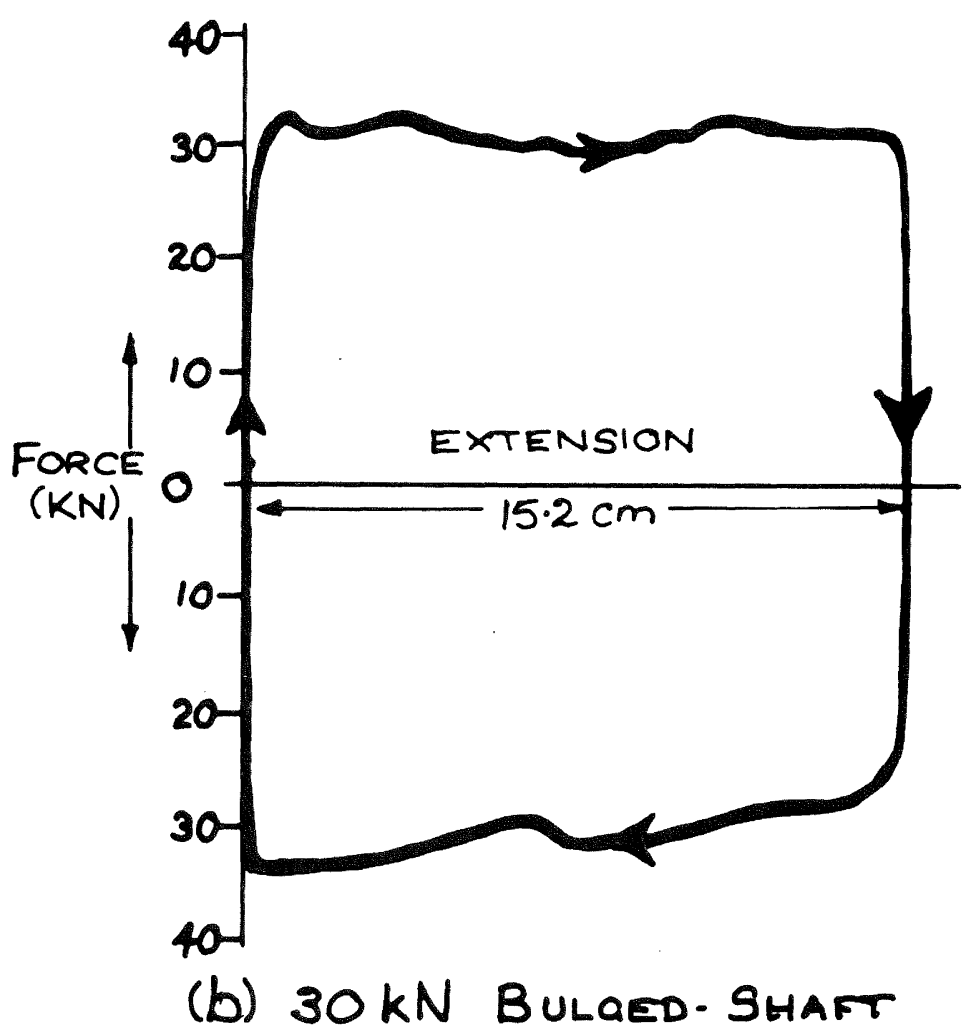

FIGURE 2: TYPICAL FORCE-DISPLACEMENT HYSTERESIS LOOPS FOR

(a) $15 \mathrm{kN}$ CONSTRICTED-TUBE ENERGY ABSORBER AND

(b) $30 \mathrm{kN}$ BULGED-SHAFT ENERGY ABSORBER, TESTED AT $1.7 \times 10-2 \mathrm{CM} / \mathrm{SEC}(1 \mathrm{CM} / \mathrm{MIN})$. 


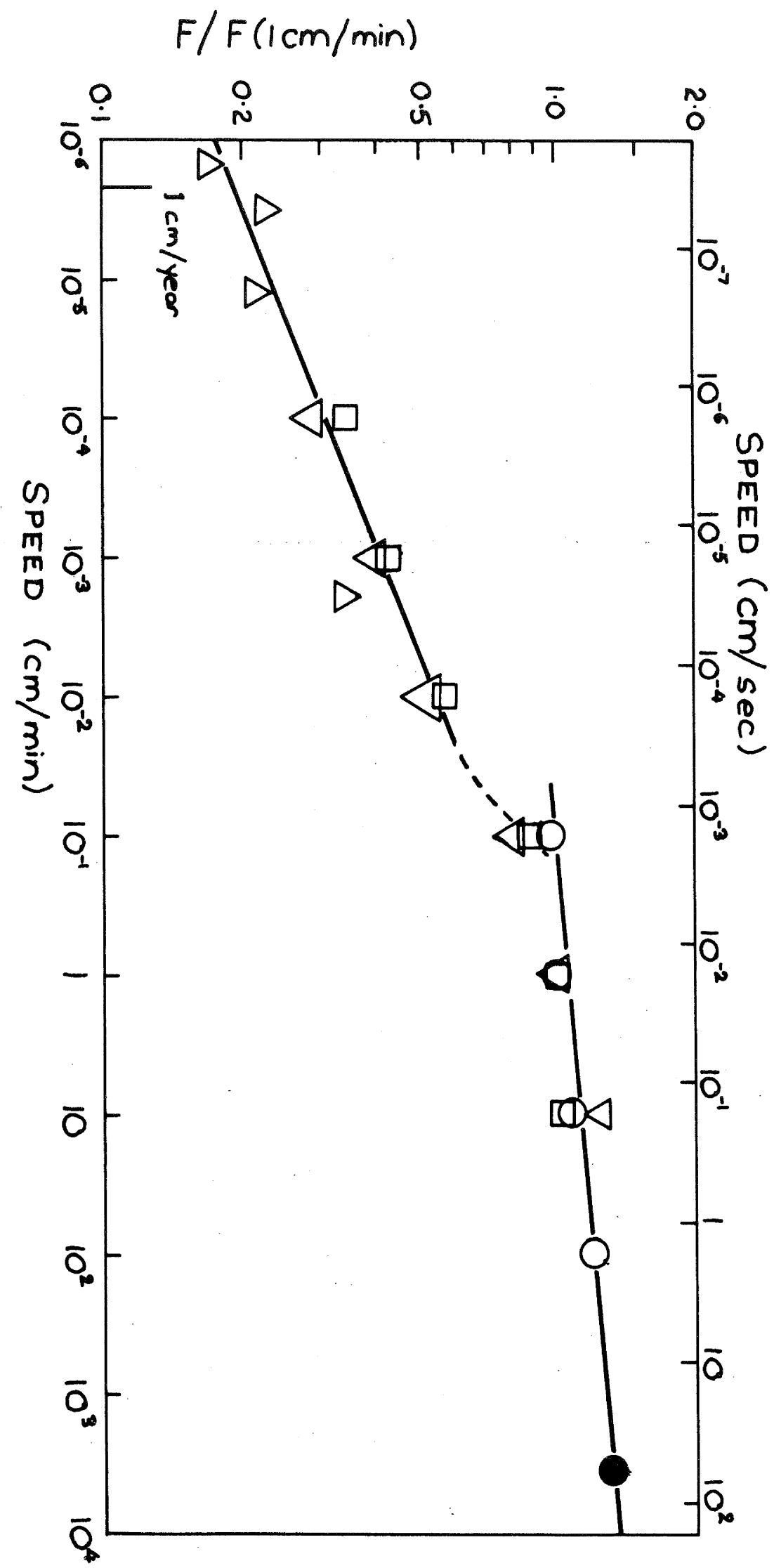

FIGURE 3: RATE DEPENDENCE OF EXTRUSION ENERGY ABSORBERS.

KEY: SYMBOL

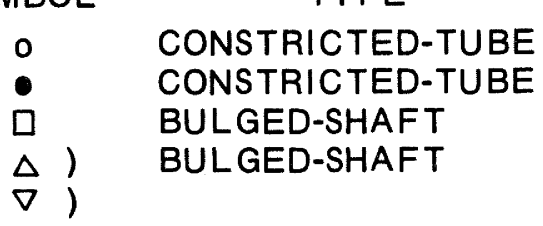

OPERATING FORCE TEST METHOD

$150 \mathrm{kN}$

$15 \mathrm{kN}$

$30 \mathrm{kN}$

$9 \mathrm{kN}$
CONSTANT RATE SHOCK LOADING CONSTANT RATE CONSTANT LOAD CONSTANT RATE 